\title{
The Impacts of User Fees on Health Services in Sub- Saharan African Countries: A Ctirical Analysis of the Evidence
}

\author{
Ejughemre Ufuoma John* \\ Department of Community Medicine, Delta State University Teaching Hospital, Oghara, Delta State, Nigeria \\ *Corresponding author: ufuoma.ejughemre@delsuth.com.ng
}

Received July 10, 2013; Revised September 05, 2013; Accepted September 16, 2013

\begin{abstract}
The momentum towards achieving the United Nations Millennium Development Goals re-invigorated concerns around sustainable health care financing and the adequacy of the financing arrangements in many lowresource settings. Accordingly, this necessitated the institution of user-fees as part of health financing reform in many countries in sub-Saharan Africa. These fees are charges levied at the point of service with the intent of reducing 'frivolous' consumption of health services, increasing the quality of services available and at the same time increasing coverage and utilisation of services. Likewise, as a 'decisive' policy to cushion the existing challenges facing health care financing in the region, a critical assessment of the assertions of proponents of user fees who use the principle of cost recovery and revenue mobilization to drive the concept of rational utilization, efficiency and equitable distribution of health care services is often exaggerated. As it were, the available evidence suggests that user fees alone will not likely accomplish equity, efficiency, or the sustainability objectives in health services in the region. What is critical is that user fees should be linked to the broader package of financing -such as insurance coverage- and with a view to averting any form of equity danger that may thus arise.
\end{abstract}

Keywords: user-fees, utilization, equity, quality, health services, sub-Saharan Africa

Cite This Article: Ejughemre Ufuoma John, “The Impacts of User Fees on Health Services in Sub-Saharan African Countries: A Ctirical Analysis of the Evidence.” American Journal of Public Health Research 1, no. 8 (2013): 196-202. doi: 10.12691/ajphr-1-8-1.

\section{Introduction}

The momentum towards achieving the United Nations Millennium Development Goals (UNMDGs) reinvigorated the concerns around sustainable health care financing and the adequacy of the financing arrangements in many low-resource settings [1]. As it were, the concern of sustainable health care financing has been a perennial challenge in low-resource settings with much attention on countries in sub-Saharan Africa [1,2]. Accordingly, this necessitated raising several options to finance health services in many countries in the region. Amongst these options was the institution of user-fees for health [3]. Notably, these fees are charges levied at the point of use for any aspect of health services and they may be charged as registration fees, consultation fees, fees for drugs and medical supplies or charges for any health service rendered, such as outpatient or inpatient care [2].

Interestingly, since the early 1980s when user charges for health services was instituted, user fee policies have however been controversial. [2] There are now debates on the impacts of these fees in helping to achieve universal health coverage more so the health targets of the United Nations Millennium Development Goals in countries in the region. Proponents for the institution of user-fees such as the International Monetary Fund (IMF) and the World Bank who promote pro-market reforms as part of their economic reforms posit that it will amongst many other things reduce budget deficits in planning for national health systems while scaling up quality of health care $[3,4,5]$. Interestingly, these reforms were also supported by the United Nations Children's Funds (UNICEF) through the Bamako Initiative that promoted 'community financing' of primary health care [4]. Additionally, the World Bank further proposes that user fee charges will improve efficiency in use of services and diminish "frivolous" consumption of health services, raise revenues to complement government budgetary allocation and therefore improve personnel motivation and service quality as well as improve equity of distribution of healthcare services in a given country through the reallocation of resources collected through user fees $[5,6,7,8]$. Equally, these organizations provide some billions of dollars in grants or loans to countries in sub-Saharan Africa and as such give them conditions that are aimed at cutting government expenditures and privatizing state-owned companies inter alia [9]. As it were, these proponents strongly recommend privatization in the form of user fees for health services, the promotion of health insurance schemes and increased investments in private care $[9,10]$.

On the contrary, opponents view the introduction of user fees in health services as a diametrical opposition 
towards the actualization of universal health coverage and as such argue that it should be reduced or even removed at the point of service [11]. Accordingly, as these contending views continue to bother health policy makers in this health "seeking" region, what is of cardinal concern is to assess the impact of user fees (such as the net benefits on efficiency and utilization of health services, equity and quality in healthcare delivery as well as resource mobilization and cost recovery in health services) in subSaharan Africa through a critical analysis of the available evidence.

\section{Benefits}

As the global search for the right policy mix to finance health care delivery, improve on health systems performance and achieve the health targets of the United Nations Millennium Development Goals in sub-Saharan Africa continues, user fees has been institutionalized in healthcare financing in the region. Of critical concern is that amidst the controversies on user fees in health services there appears to be potential benefits of it hitherto, however, this necessitates a critical analysis.

\subsection{Efficiency and Utilization}

Experts who promote user charges in health services view it as a pricing device which signals users and providers of health services as well as health planners in charge of health service outlets on how best to manage health resources through payment for services. [12] Supporting arguments for these fees in health care delivery have it that, user fees as an efficiency enhancing tool in health care delivery encourages rational utilization of services by limiting "frivolous" or "unnecessary" use of health services, reducing inappropriate referral of patients while increasing the level of accountability which service providers give clientele and the community in general $[12,13]$. Some health-financial experts also suggest that a token being made for payment at the point of service will lead to increased precautionary measures against illnesses by members of the community and hence reduce any form of overcrowding in health service outlets [14]. While these views appear to be economically sound, they have their merits and demerits. A closer look at the available evidence will provide further insights from which judgements can be made thereof.

Although there is not an avalanche of evidence on the impacts of user fees on efficiency and utilization of health services in the region, findings from a Cochrane review conducted between November 2005 and April 2006 has it that of the sixteen included studies for review only five studies found out that introduction of user fees resulted in some form of regulation in utilization of health services [2]. Further findings from the review showed that when user fees were introduced or increased, peoples use of preventive and curative health-care services decreased [2]. On the contrary, a reduction or removal of these charges often resulted in increases by all particularly outpatient use mainly for curative services, by thirty to fifty percent approximately [2]. More so, further evidence from a number of studies in countries in sub-Saharan Africa have shown that the introduction or increment in user fees led to a general decrease in peoples use of both preventive and curative healthcare services at all levels of health care delivery (primary to tertiary) [15,16,17]. Equally, a longitudinal study from Lesotho (a southern African country) revealed that increments in user fees led to a dramatic decline in utilization [18]. In the same vein, there is evidence from Gabon [19] which showed that when consultation fees were increased in a municipal health centre there was a drop in outpatient visits [17]. However, the reverse was the case following a decrease in user fees [19]. Other revelations from Sudan [20], Kenya [21,22], South Africa [23] and Uganda [24] have findings which are congruent to the evidence from Gabon and Lesotho $[18,20]$. In Sudan, researchers showed that decreasing user fees by twenty-five percent led to a more than proportional change in the number of pregnant women and children seen in health centres by fifty-two percent and sixty-four percent increment respectively [19].

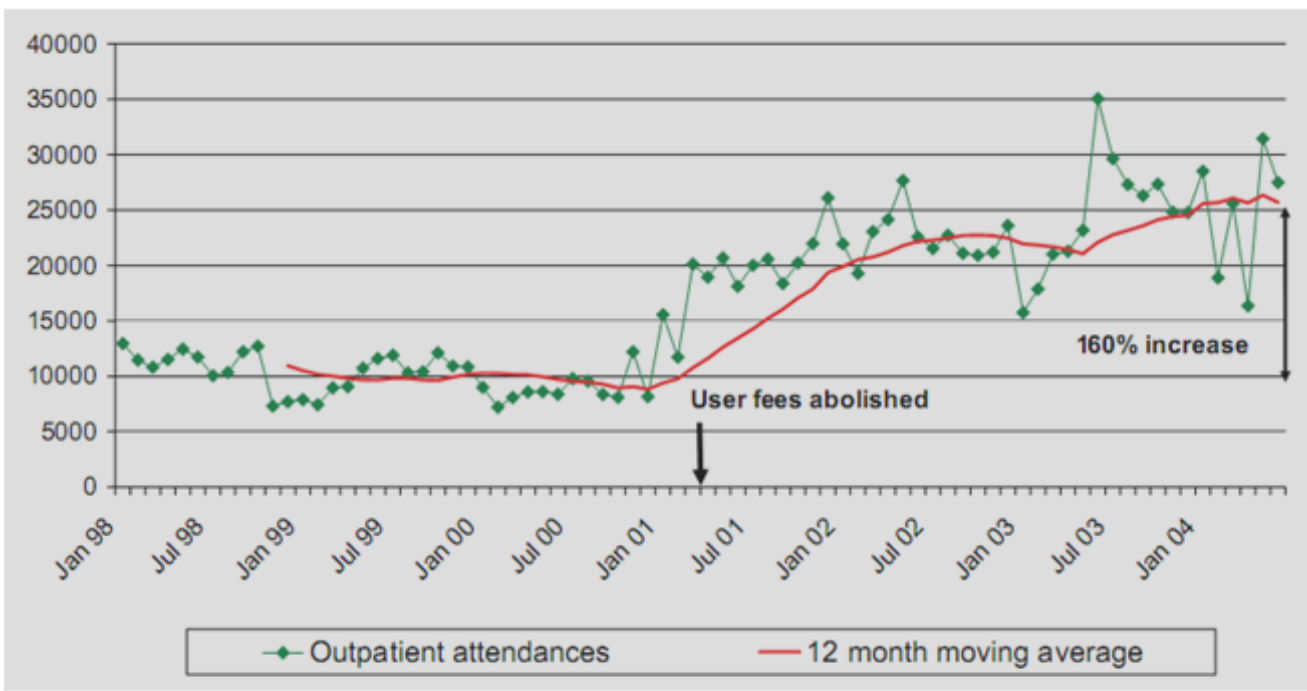

Source: Meessen, et al., 2009. Removing User Fees in Low income countries: A Multi - Country Review

Figure 1. Outpatient attendances in Uganda between 1998 and 2004 
Furthermore, contrary to the views of proponents of user fees in the region, an analysis from a multi-country review conducted to assess the impact of removal of user fees in six countries in the region ( Burkina Faso, Burundi, Ghana, Liberia, Senegal and Uganda) had it that following the reduction or complete removal of user charges there was a systematic increase in clientele utilization of health services within a period of six years (i.e from 1998 to 2004) [1]. Given this, it is interesting to take closer look at Figure 1 above (an extract from the multi-country review) which shows that following a policy change that led to the removal of user fees in Uganda particularly, the new out patients contacts in the outpatient department (OPD) of most health centres under review rose by a proportion of 0.56 per capita in 2001/02 and to 0.72 in 2002/03 and then to 0.79 in $2003 / 04$. Further elucidation by household surveys did confirm an increase in the utilisation of public health and private services as well $[1,25]$.

Additionally, it could be said that while user fees functions to ration health service utilization, many healthclienteles are usually not in the position to determine the severity of their symptoms or health needs; the import being that user fees could be a barrier to diagnosis and treatment. [26,27] This because, for instance, an individual who contracted the human immunodeficiency virus (HIV) without having the clinical evidence of the disease cannot ascertain his/her status without having to first consult a health centre where consultation fees will be made after which screening could be done even if the screening procedure were free. The same applies to other health problems in most lowresource settings in the region. These suggest that user fees could have a negative impact on the quantitative outcome of clientele-base in health services, particularly in those areas with high disease burden and low income per capita. Furthermore, as a measure to ration health service utilization; the affluent in the community could for "frivolous" reasons seek and consume health care at the expense of the poor and needy. Accepting this, will query the rationale' of rational utilization made by proponents of user fees. Accordingly, it might be concluded that although the supporting evidence is limited, in theory fees may encourage more efficient utilization patterns, it decreases the per capita utilization of health services in countries in the region by promoting "inefficiencies" in clientele behaviour towards utilization of health services. This therefore negates the aim of universal health coverage amidst the ever increasing health care burden in sub-Saharan Africa.

\subsection{Equity and Quality}

As the implication of user charges on utilization of health services in sub-Saharan Africa draws further interest, the issues of efficiency, equity and quality are of critical consideration, as user fee systems are associated with parallel actions that influence the distribution of benefits associated with using health care which is important for equity and quality of care. [28] Indeed, it follows that advocates for user fees have suggested that the provision of health services free of charge or at very low prices does little to improve equity in health coverage. [29] This is because health resources are limited and price rationing is crucial in order to provide services for those who are in need of it. Proponents strengthen their case by arguing that the provision of health care is akin to normal goods and as such having positive income and positive price elasticities so that those with higher earning per capita consume more of the goods. [30] This according to them will then provide more financial resources which can be used to improve the quality of care. Additionally, proponents believe that equity in terms of coverage is better served by using user fee revenue to expand coverage services and improve quality such as in drug supply and adequate storage facilities, upgrading and improving of health facilities, maintenance of equipment and other health facilities, with keen interest in underserved areas in developing economies of which subSaharan Africa comes to bear. [31] But this brings concern as to whether the revenue generated from these fees will be sufficient to augment national expenditure on health care delivery in a region challenged with the knotty and monumental problem of health inequality and the high burden of diseases and were out-of pocket expenditure contributes more than fifty percent for health financing, driving millions of people every year into poverty and their untimely death due to catastrophic health expenditure. $[32,33]$ However, proponents suggest that there will be further improvement in the availability and quality of services as the "freed" expenses on government resources for health following user charges in health service centres are rechanneled towards other underfunded health programmes that provide benefits for the pubic while increasing coverage of benefits for the socio-economically deprived. It is further posited that these improvements in coverage and quality will make public health service centres more attractive to all income groups considering that equity, quality and utilization are improved in the long run.

Nevertheless, contrasting views have rather suggested that fees by themselves tend to dissuade the socioeconomically deprived from using health services more than the well-off and these fees are associated with delays in accessing care and with increased use of selfmedication and informal sources of care. [34] Equally, there appears to be the general consensus that user charges do not generate adequate revenue or to be associated with the resource reallocations necessary to enable substantial and sustained improvements in health care for the poor in most part of the region [28].

Given the above background on views of user charges on the quality of health services, Figure 2 reveals that in Ghana the introduction of user fees in health centres had an impact on the quality of service provided for deliveries needing skilled services. [1] Analytical findings showed that following the implementation of user fees policy in 2004 in health centres in several districts, there were increases in the skilled delivery coverage in most health facilities in the country. However, as the years continued these quality services declined gradually. This is unsurprising since the quality of services (particularly curative interventions) are directly associated with adequate financing of health services. That is to say, in mobilizing, paying of skilled health workers as well as retaining them requires money. It will not be out of context to assert that in a region where many of its populace live on less than one dollar per day (i.e socioeconomically deprived), there will be the low motivation 
to consume health services especially with high price tags attached to them. It might then be concluded that, while user fees may increase the quality of health services provided, it reduces equity in terms of coverage of health care delivery in the region, hence supporting the need for alternative sources of healthcare financing.

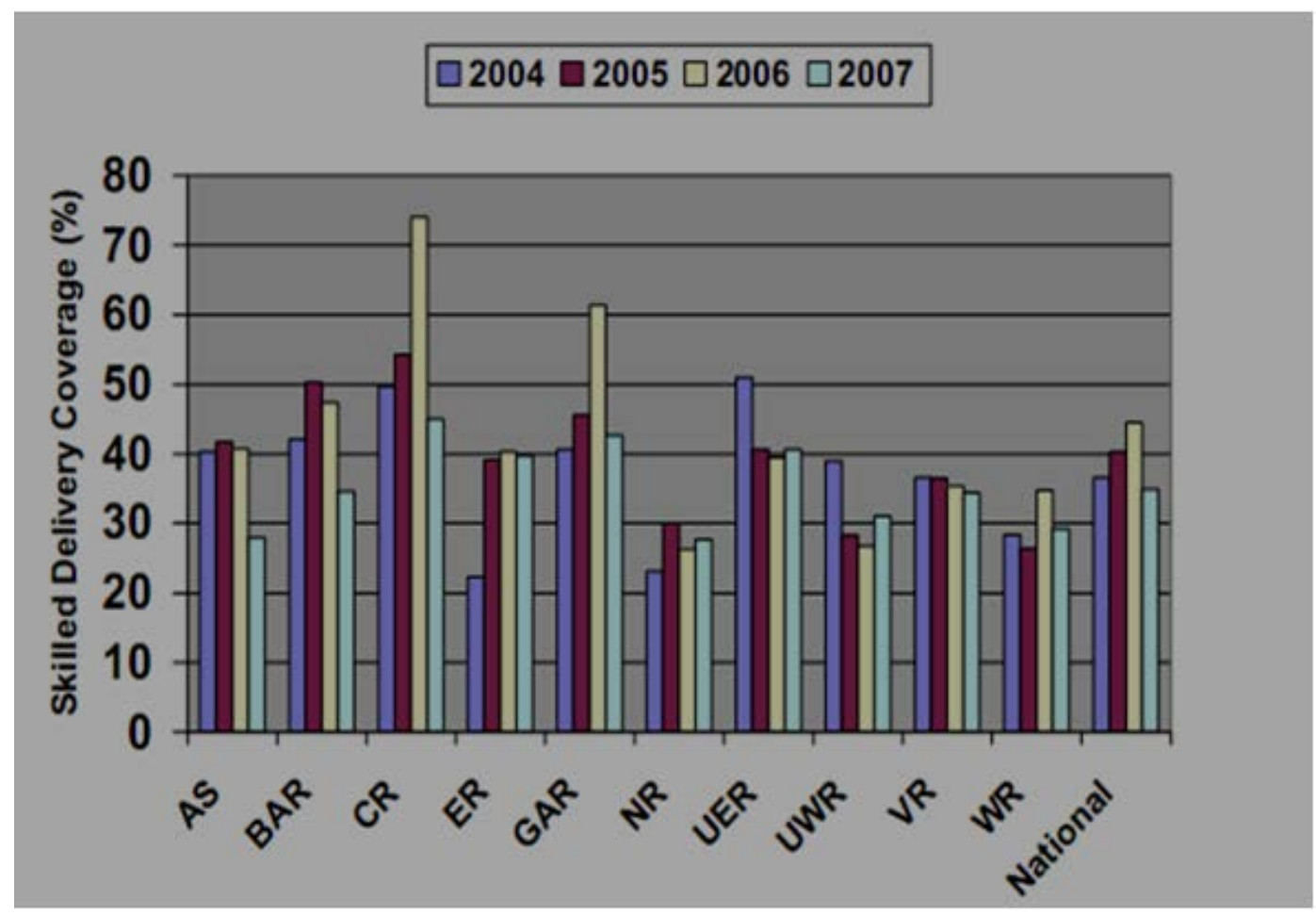

Figure 2. Skilled delivery per region in Ghana between 2004 and 2007.(Source: Meessen, et al., 2009. Removing user fees in low income countries: a multi -country review)

\subsection{Resource Mobilization and Cost Recovery}

Most commonly, advocates for the implementation of user fees argue that it increases financial resources for the health sector and helps to soften the pressure on governments in budgeting for health while efforts are made to improve the quality and coverage of basic health. $[5,14,31]$ It is further suggested that relying on user charges reduces the cost burden on public systems by shifting part of the cost responsibilities to the end users and decreasing the total volume of services consumed thus easing many of the economic burdens of the government. [29] As it were, the proposal of the World Bank has it that inter alia, charging for curative health services reduces the burden of curative services on national health budgets and complements internally generated revenues (IGR) that could be used to cover costs of other underfunded health programmes particularly at primary health care level. [29] It further adds that these revenues will be redirected for preventive programmes such as vector control, health education and environmental sanitation.

Table 1. Cost Recovery Levels in National User Fee Systems in sub-Saharan African Countries and Years (\%)

\begin{tabular}{|c|c|c|}
\hline Country & Year & Cost Recovery Level (\%) \\
\hline Botswana & 1983 & 2.8 \\
\hline Burkina Faso & 1981 & 0.5 \\
\hline Burundi & 1982 & $3.1,7.2$ \\
\hline Côte d'Ivoire & 1986,1993 & $15.0-20.0$ \\
\hline Ethiopia & $1984-86$ & $12.0-13.0,5.0-6.0$ \\
\hline Ghana & $1987,1990-91$ & 0.5 \\
\hline Guinea Bissau & 1988 & 2.1 \\
\hline Kenya & 1993 & 9.0 \\
\hline Lesotho & $1991-92$ & $1.2-7.0$ \\
\hline Mali & 1986 & 12.0 \\
\hline Mauritania & 1986 & $8.0,1.0$ or less \\
\hline Mozambique & 1985,1992 & $4.4-7.0$ \\
\hline Senegal & 1986 & $2.2,4.6$ \\
\hline Swaziland & $1984-85,1988-89$ & 3.5 \\
\hline Zimbabwe & $1991-92$ & \\
\hline
\end{tabular}

Source: Adapted from Gilson, Russell and Buse (1995).

On the contrary, that user fees could be a sustainable option in health financing in low income countries, it will be of interest to note that in sub-Saharan Africa, the revenue mobilization from user fees has been more 
theoretical than practical. Of critical concern is that with contextual findings of cost recovery in health systems financing in the region. As it were, there is substantial evidence that suggests that revenue from these charges have not been significant and vary over time. [28] As illustrated in Table 1 above, reports show low cost recovery levels as a percentage of health systems financing in different countries in the region. More evidence reveals that while there were instances of marginally increasing revenues, possibly as a result of improved implementation practices, in other instances there were decreasing revenues as a result of inflation or problems such as war or economic recession which has being the case in many settings in the region. [35] Equally, statistical reports now show that on the average user fees have provided for less than twenty percent of governmental recurrent expenditure for health in most setting in sub-Saharan Africa. [36,37] It has been shown that as against the expected, these fees yielded only twelve percent of the gross operating costs for health services in countries like Ghana and a meagre one percent in Burkina Faso. [38,39] Approximately, most national user fee systems in the region have generated only about five percent of total recurrent health system expenditures and gross administrative costs [35,39,40].

Additionally, the revenue generating potential of user fees in the many settings in sub-Saharan African countries is further constrained by weak administration and management capacities [35], inefficiencies in information systems and supply managements in health care delivery and poor structural and legal frame works required to regulate the policies of government ${ }^{35}$ as well as the fact that in most settings in the region revenue generation levels are constrained by the need to keep fees low, because household income levels are low. [41,42] Furthermore, with the current poor revenue generation for financing health care delivery by these charges, the situation in the region is compounded by poor community participation in setting up these fees. [44,45] Several authors have adjudged the implementation of these as poor in that these charges are imposed on the community by governments and other constituted authorities with little or no prior consultation of the populace. [43,44,45] Anecdotal reports have it that even when social advocacy groups try to make meaningful policy contributions, their suggestions will not be considered for policy. As it were, the jingles surrounding community participation in financing of health care delivery is a far cry from the observed reality in many settings in sub-Saharan Africa when it comes to user fee policy. Consequently, it is then crucial to state that while these fees may generate relative proportions of the total expenditure for health care delivery, however, user fees policy cannot bridge the wide gap needed to finance health care delivery in a region where there is the knotty and monumental problem of high disease burden which is further exacerbated by wide spread poverty in many of its communities.

\section{Recommendations}

With rising concerns around the need for sustainable health care financing in sub-Saharan Africa, the situation in the region reveals that user charges can play an important role in health services. However, a critical assessment of the assertions of proponents of user fees who often use the principle of cost recovery and revenue mobilization to drive the concept of rational utilization, efficiency and equitable distribution of health care services is often exaggerated. As it were, the available evidence suggests that user fees alone will not likely accomplish equity, efficiency, or the sustainability objectives in health services in the region. Equally research evidence from the region shows that when these policies are poorly designed and implemented, they can subvert equity objectives. [35] This suggests that charges levied for health services should therefore be viewed as one of the fundamental or irreducible components in a broader health care financing package. Furthermore, as these charges may be important in the development of other health financing systems; implementing these should be linked to the broader package of financing (such as health insurance coverage) and with a view to averting any form of equity danger that will thus arise. Accepting this implies that efforts made to achieve equity, efficiency, and in particular, sustainability requires implementing a wider policy package that will include the development of skills, systems, and mechanisms needed to ensure effective implementation thereof.

In all, as the need for a policy reform now comes to bear in health financing in the region, what is obtainable is that most literatures have only been able to provoke more debate on user fees and their impacts on utilization, equity and coverage but has left a number of issues unresolved. This now calls for further research into user charges and the impact on health services in order to inform policy in a health seeking region.

\section{Conclusion}

As commitments to improving on healthcare delivery in Sub-Saharan Africa continues, there is the need to achieve much more if all countries in the region are to meet the health targets of the millennium development goals. User fee is only a part of the development picture. Consequently, there is now the need for more robust health policy reforms that will reduce the regressive burden of out-of pocket expenditure and at the same time overdependence on government budgetary allocation to health.

\section{Methods for Review}

As literature reviews are summaries of research evidence that address research issues by using explicit methods to identify, select, critically appraise relevant research studies and analyse data from the studies that are included for the review, the author made this study as inclusive as possible.

\section{Search methods:}

This involved a broad search on user fees in subSaharan Africa from international databases. Using key words, the author searched a number of international databases, including: Cochrane data base, PUBMED, MEDLINE, EMBASE, Google Scholar, websites and online resources of international organisations as well as 
hand searches of bibliographic records. However, the author did not contact experts or universities. Original searches were conducted the between March 2013 and April 2013 and this generated 15 original studies that were included for the review from 50 initial studies.

\section{Selection criteria:}

To generate evidence for the review, studies between 1980-2012 were considered and findings included were from reviews, expert commentaries cross sectional studies, field trials, interrupted time-series studies and controlled before-and-after studies that reported an objective measure of at least one of the following outcomes: healthcare utilization and coverage, quality of health, health expenditures, or health outcomes.

\section{Data collection, analysis and findings:}

As the study is not a systematic review there was no detailed data synthesis and quality assessment to generate evidence for the review, however, the findings generated from all included studies formed the themes used to critically analyse the impacts of user fees on health services in the region. Summarily, it was found out by almost all studies that when fees were introduced or increased, health services decreased significantly.

\section{Author's Statement}

This paper clearly expresses the views of the author as there are no competing interests. For enquires on the views of this document please contact the author.

\section{Acknowledgements}

I give all gratitude to God Almighty for his inspiration and the suggestions of the anonymous peer reviewers.

\section{References}

[1] Meessen B., Hercot D, Noirhomme M., Ridde V., Tibouti A, Bicaba A.,Kirunga C., Tashobya and Lucy Gilson.Removing user fees in the health sector: A Multi-Country Review. United Nations Children's Fund (UNICEF), 2009.

[2] Waiswa W.P. The impact of user fees on access to health services in low- and middle-income countries: RHL commentary (last revised: 1 May 2012). The WHO Reproductive Health Library; Geneva: World Health Organization.

[3] Meessen B, Hercot D, et al. Removing user fees in the health sector: a review of policy processes in six sub-Saharan African countries. Health Policy and Planning 2011; 26(20):16-29.

[4] McPake B. User charges for health services in developing countries: a review of the economic literature. Social Science and Medicine, 1993. 36; 11:1397-405.

[5] World Bank 1987. World Bank. Financing the health sector: an agenda for reform. Washington, DC: The World Bank, 1987.

[6] World Bank. 1993. World Development Report 1993: Investing in Health. New York: Oxford University Press.

[7] Griffin, C.. "Welfare Gains from User Charges for Government Health Services." Health Policy and Planning 1992. 7(2):177-180.

[8] Shaw, P., Griffin C. Financing Health Care in Sub-Saharan Africa through User Fees and Insurance. Washington, D.C.: World Bank. 1995.

[9] Third World Network: World Bank and IMF are responsible for Africa's Health Crisis. 2002. Available online at < http://www.twnside.org.sg/title/twe279g.htm $>$ Accessed $6^{\text {th }}$ July,2013.

[10] World Health Organization (WHO). Evaluation of Recent Changes in the Financing of Health Services: Report of a WHO
Study Group. Technical Report Series No. 829. Geneva: WHO. 1993.

[11] Dumoublin, J., Kaddar M., Velasquez G. Access to Drugs and Finance: Basic Economic and Financial Analysis. WHO/DAP/91.5. Geneva: World Health Organization. 1991.

[12] Griffin C. User Fees For Health In Principle And Practice. EDI Seminar Project. World Bank. Washington DC,1987.

[13] Shepard and Benjamin. User Fees in Health Financing in Developing: mobilizing financial resources for health. In Health Nutrition and Economics crises: Approaches to policy in the third world. Bell D Reich M (eds). Auburn House Publishing Company. Dover MA. 1988.

[14] Mwanbu G. Financing Health Services in Africa: an assessment of alternative approaches. PRE working paper 457. World Bank: Washington DC,1990.

[15] Diop F, Yazbeck A, Bitran R. The impact of alternative cost recovery schemes on access and equity in Niger. Health Policy and Planning 1995;10(3):223-40.

[16] Bratt JH, Weaver MA, Foreit J, De Vargas T, Janowitz B. The impact of price changes on demand for family planning and reproductive health services in Ecuador. Health Policy and Planning 2002;17(3):281-7.

[17] Issifou S, Kremsner PG. Impact of increasing consultation fees on malaria in Africa. Wiener Klinische Wochenschrift 2004;116(910):332-3.

[18] Bennett S. The Impact of the increase in user fees: A preliminary investigation. Lesotho Epidemiological Bulletin.1989; 4:29-37.

[19] Lagarde M., Palmer N. The impact of user fees on access to health services in low and middle-income countries. Cochrane Database of Systematic Reviews 2011; 4.

[20] Abdu Z, Mohammed Z, Bashier I, Eriksson B. The impact of user fee exemption on service utilization and treatment seeking behaviour: the case of malaria in Sudan. International Journal of Health Planning and Management 2004;19(1):95-106.

[21] Moses S, Manji F, Bradley JE, Nagelkerke NJ, Malisa MA, Plummer FA. Impact of user fees on attendance at a referralcentre for sexually transmitted diseases in Kenya. Lancet 1992;340(8817):4636.

[22] Collins D, Quick J, Musau S, Kraushaar D, Hussein I. The fall and rise of cost sharing in Kenya: the impact of phased implementation. Health Policy and Planning 1996;11(1): 52-63.

[23] Wilkinson D, Gouws E, Sach M, Karim SS. Effect of removing user fees on attendance for curative and preventive primary health care services in rural South Africa. Bulletin of the World Health Organization 2001; Vol. 79, issue 7: 665-71.

[24] Burnham G, Pariyo G, Galiwango E, Wabwire-Mangen F. Discontinuation of cost sharing in Uganda. Bulletin World Health Organization 2004; Vol. 82, issue 3:187-95.

[25] Meessen, B. Removing user fees in the health sector in lowincome countries: A policy guidance note for program managers. UNICEF, New-York. 2009.

[26] Abel-Smith, B., and P. Rawall. "Can the Poor Afford 'Free' Health Care: A Case Study of Tanzania." Health Policy and Planning. 1992;7(4):329-41.

[27] Stanton B., Clemens J. User Fees for Health Care in developing countries: A case study of Bangladesh. Social Science and Medicine. 1988, 39(8):1105-1115.

[28] Russell, S., and L. Gilson. "User Fees in Government Health Services: Is Equity Being Considered? An International Survey." PHP Publication no. 15. London: London School of Hygiene and Tropical Medicine. 1995.

[29] Seperhi A., Chernomas R. Are User Charges Enhancing Efficiency and Equity Enhancing? A Critical Review of the Economic Literature with particular reference to experience from developing countries. Journal of International Development. 2001; 13:183-209

[30] Baker J., van de Gaag, J. Equity in health care and health care financing. Evidence from five developing countries. In Equity in the Finance and delivery of health care: An International Perspective. Oxford University Press.1993.

[31] de Ferranti. Paying for a Health Services in Developing countries: An Overview. Staff working paper,721. World Bank, Washington DC.1985.

[32] Meessen B, Zhenzhong Z, van Damme W et al. Editorial: Iatrogenic poverty. Tropical Medicine and International Health. 2003; 8: 581-4. 
[33] Frenk J, Gonzalez-Pier E, Gomez-Dantes O, Lezana MA, Knaul F. Comprehensive reform to improve health system performance in Mexico. The Lancet. 2006; 368: 1524-34.

[34] Booth D.,et al. Coping with cost recovery: a study of the social impact of and response to cost recovery in basic services (health and education) in poor communities in Zambia.1995.

[35] Gilson, L., S. Russell, and K. Buse. "The Political Economy of User Fees with Targeting: Developing Equitable Health Financing Policy.” Journal of International Development. 1995; 7(3):369-402.

[36] World Health Organization. Guideline for Implementing the Bamako Initiative. Regional Committee for Africa, thirty eigh session, Brazaville.7-14 September,1988.AFR/RC38/18. WHO: Geneva.

[37] Chabot J. Effect of a drug and sharing system on prescribing and utilization. A controlled trial from Nepal. Health Policy and Planning. 1995; 10(4):423-430.

[38] Vogel R. Cost Recovery in the Health Sector in Sub-Saharan Africa. International Journal of Health Planning Management. 1991; 6:167-191

[39] Norlan B., Tublat V. Cost Recovery in Public Services in SubSaharan Africa.EDI Seminar Series. World Bank, Washington DC.1995.
[40] Kutzin, J. "Experience with Organisational and Financing Reform of the Health Sector." Current Concerns Strengthening Health Services Paper no. 8. WHO/SHS/CC94.3. Geneva: World Health Organization. 1995.

[41] Gilson, L., and A. Mills. "Health Sector Reforms in Sub-Saharan Africa: Lessons of the Last 10 Years." Health Policy 1995. 32(13):215-43.

[42] McPake, B., K. Hanson, and A. Mills. 1992. "Implementing the Bamako Initiative in Africa: A Review and Five Case Studies." PHP Departmental Publication no. 8. London: London School of Hygiene and Tropical Medicine.

[43] Oakely P. Community Involvement in Health Development: An Examination of the Critical Issues. World Health Organization. Geneva. 1989.

[44] Gilson, L. "Government Health Care Charges: Is Equity Being Abandoned?” EPC Publication no. 15. London: London School of Hygiene and Tropical Medicine. 1995. "Management and Health Care Reform in Sub-Saharan Africa." Social Science and Medicine. 1988; 40(5):695-710.

[45] Lupton D. The Imperative of Health: Public Health and the regulated Body. Sage. London.1995. 